\title{
Braincrafting: Why Playing Video Games is Good for you
}

\author{
Katarina Fatur \\ University of Ljubljana \\ Faculty of Arts, Ljubljana \\ Slovenia \\ katarina.fatur@gmail.com
}

\begin{abstract}
In the article I present cognitive, emotional and social benefits of playing video games, suggest simple guidelines for ethical evaluation of gaming, and offer an overview of findings which support the use of video games for cognitive enhancement and social collaboration.
\end{abstract}

Keywords: Video Games, Cognitive Enhancement, Attention, Complex Problem Solving, Brain Plasticity, Learning, Consequentialism

Received: 1 October 2018, Revised 11 December 2018, Accepted 17 December 2019

DOI: $10.6025 / \mathrm{jic} / 2019 / 10 / 2 / 60-65$

(C) 2019 DLINE. All Rights Reserved

\section{Introduction}

In the past, research has been mostly focused on the negative effects of video games, but in the last decade, a growing number of studies has supported the view that playing video games may significantly enhance our cognitive abilities and agility. These contradicting facts fuel the discussion on whether playing video games is harmful or not. Here I focus on the benefits of gaming and offer an overview of findings which support using video games as tools for cognitive enhancement and social collaboration, while also outlining the ethical framework which is to be followed in order to avoid negative aspects of gaming.

\section{Proposed Ethical Framework to Evaluate Video Games}

Up until a few years ago, research has been mainly focused on the potential adverse effects of video games, such as increased aggression [1] [2], addiction to gaming [3] and increased obesity risk [4]. While I do not believe that gaming is inherently bad, I can understand the reservation and caution. For better or worse, playing video games significantly changes our brain [5], which carries serious implications. With our growing understanding of the brain comes greater responsibility about how to apply this knowledge in a benevolent manner. If we consider video games as a tool for self-improvement and cognitive enhancement, they should align with (neuro)ethical guidelines which govern any other means for cognitive therapy. Ethics is a set of principles which prescribe what is right or wrong in terms of rights, obligations, or benefits for individuals and society. The subfield of neuroethics, which is focused particularly on the issues in neuroscience, is less than 20 years old. The concept was first introduced in 2002, when William Safire defined it as "the examination of what is right and wrong, good and bad about the treatment of, perfection of, or unwelcome invasion of and worrisome manipulation of the human brain" [6]. Video games possibly constitute a case of 'worrisome manipulation' and open a window for 'unwelcome invasion' of the brain, but at the same time they can also act as one of the most pleasurable and safe brain enhancement tools. Do benefits warrant the dangers?

\begin{tabular}{llllll}
\hline 60 & Journal of Intelligent Computing Volume & 10 & Number 2 & June & 2019 \\
\hline
\end{tabular}


To do good, we first have to determine what is good. The ethical framework to help us evaluate the 'goodness' of video games in this article is an epicurean-like teleological/consequentialist theory of ethics with a bit of pragmatism, where we pursue good and pleasurable outcomes, where an action's value is based on the outcome of that action, and where the evaluation whether the outcome is good or bad might shift when new scientific discoveries are made. It appears that this ethical framework fits neuroscience research better than other normative ethical theories, simply because the subjective virtuous conduct of game-designers (virtue ethics) or a scientists' firm belief that undertaking experiments is the right thing to do (deontological ethics) is of little or no importance in comparison to unwanted, but nonetheless possibly detrimental effects a person might suffer as the consequence of her or his invaded and changed brain.

The last conclusion partly rests on the notion of 'fairness' - it is not fair that a player would be harmed for the sole purpose of advancing science, or because the game designer made a mistake despite the designer's moral character being impeccable. Fairness can be fostered by assuming equality of all involved parties and by clear and honest communication, where the gaming industry candidly informs the player about possible effects. Informing the player is also the prerequisite for the player to give their consent to undergo a benevolent cognitive manipulation when playing a game. At the same time, the player should provide feedback, so that the industry can align and improve their practice. This also involves the issue of privacy protection, especially in the case of collecting neurodata in neurogaming ${ }^{1}$.

Simply put, for gaming to be ethical, it has to benefit the player and it has to fulfill three criteria: it should result in positive, useful outcome for the gamer and/or society, it should respect and protect gamer's privacy, and the gamer must participate knowingly and willingly. Since new technologies pose difficult ethical questions and could be easily used for ill intentions, it is important to show, why is it worth to undergo the gaming experience despite the risk, or even better, while avoiding the risk. In the following sections I offer an overview of beneficial uses of video games and discuss how they affect the brain.

\section{Benefits of Video Games}

Video games have become increasingly diverse and complex, (hyper)realistic, and socially engaging. It has been shown that playing certain types of video games may enhance perceptual, motor, social, emotional and cognitive learning [8]. While scientists still do not know exactly how different brain regions interact, or what is the role of each and every particular neuroanatomical element, some hypotheses have been made in studies researching the impact of gaming on brain plasticity. Below I present the supporting studies in more detail.

\subsection{Learning}

At a neuroethics conference in $2013 \mathrm{C}$. Shawn Greene explained that the adult brain does not want to learn anything new, because learning entails costly brain tissue restructuring [9]. So, how do games facilitate learning and foster neuroplasticity? An incentive for the brain to more readily learn something new is the possibility of a reward at the end [9]. A study by Shaowen Bao and his team has shown that when stimulation of the dopaminergic system occurs at the same time as a particular tone is played, over time a larger area of auditory cortex is allocated to process that particular frequency of sound [10]. The brain structurally changes itself in order to more accurately and quickly process the input that will reward it with dopamine release. Games foster learning because they activate the reward system.

Circumstances which bathe the brain in rewarding hormones are also excitement and exploratory behavior [11], which both abound in challenging, but ultimately safe virtual environment of your favorite game. Learning is further encouraged by the fact that you can safely fail - paired with novelty and flexibility of the play, safe environment promotes creativity [12]. In addition, the

\footnotetext{
${ }^{1}$ In neurogaming, the player's heart rate, brain activity, facial expressions, voice, skin conductance, eye movement, pupil dilation, and similar indicators are measured in order to use the input to dynamically adjust the gaming content and provide a completely personalized, immersive gaming experience, which takes into account the player's emotional and cognitive state [7]. In this way, the desired (or feared) cognitive manipulation is perfectly suited to the player. Some game engines allow the players to navigate the game merely by directing their gaze or blinking. Future development also includes different techniques which will simulate certain sensations, e.g. the player holding an object in their hand while there is no object there [7]. The ethical concerns are significant, but in this article I mainly focus on the benefits of gaming and mention neurogaming merely as an interesting new branch of the industry, and my purpose is to show, why it is worthwhile that we acknowledge and tackle these ethical issues to be able to benefit from our gaming experience as much as we can.
} 
immediate feedback evaluating the player's game (leveling-up, points, new abilities and tools), present a perfect ground to acquire an 'incremental theory' of players' ability, where the players believe that they can change and actively improve their skills by investing more time and effort [8]. How is this useful in real-life scenarios? The learned skills can be transferred, as illustrated by the examples below.

\subsection{Visual Attention}

Green explains that action games exhibit particular qualities, which sharpen a gamer's visual attention [9], such as: complex 3D environment, fast motion, transient visual stimuli, and heavy perceptual load with several events occurring simultaneously, where not all events are important. 15 years ago Green and Bavelier demonstrated that selective visual attention improves with playing action video games, with effects lasting for 6 months after the last training [13]. In more complex multiplayer first person shooter games, there is also a heavy cognitive load: the player has to observe certain strategy and keep track of other players' actions. While primary visual focus is centrally on the screen, peripheral vision is fully engaged as well, since important elements tend to pop up from the sides.

The causal relationship between playing action games and improved players' ability to coordinate visual input with their motor control was shown in 2016 [14]. Players who played action games for 5 hours per week over 6 months were later retested for their driving abilities and they exhibited better lanekeeping and visuomotor-control skills. Cognitive gains acquired in gaming are thus transferable to real-world visual ability.

Another example of induced neural plasticity in the players' visual system is the case of adult amblyopia ('lazy eye') patients, whose fundamental visual functions improved from 16-54\% after playing action video games [15]. It was a small scale pilot study, but researchers are optimistic about the possibility to apply the principles to treating other cortical dysfunctions as well. Additional benefits of playing action games in relation to vision are improved visual attentional skills in dyslexic children [16]. Without any direct reading training, the reading abilities of these children improved significantly after only 12 hours of playing action video games.

\subsection{Multi-tasking}

Each time we switch our attention from one task to another we pay a small cognitive cost and playing action games helps to reduce this cost [9]. In our everyday life we often have to multitask, and the cumulative time spent in task switching is relevant. The positive effects that action games training has on the brain is lasting and can still be observed months after the last gaming session. This effect is also applicable in serious, complex real-life events such as surgery. When novice surgeons played action games for prescribed period of time, the result was a significant improvement in their ability to perform surgery [17]. Even more surprisingly, surgical skills could be better predicted by their screen time than by the number of surgeries performed, or even the amount of time spent practicing the surgery.

\subsection{Social and Emotional Support}

Multiplayer online games which engage thousands of people from all over the globe are probably the most exciting, rewarding and productive development in the realm of video games. Immersive social contexts not only provide a playground to develop social skills, but also serve as a solid source of emotional support and resilience, which I present in more detail below.

Massive multiplayer online games (MMOGs) encourage the development of online communities, with associated attachments and social rituals [18]. These communities represent a suitable model for a variety of human societies [19], because they exhibit a strong sense of social connection, identification with other members of the group and a sense of distinguishing themselves from other groups, as well as a strong commitment to the group [18], [19]. On the continuum from Gemeineschaft (communal society) to Gesellschaft (associational society) [20], where the first originates from solidarity, social union and spontaneous expressions of emotions in personal relationships, and the second is established on rational self-interest with less emphasis on kinship and personal relations, MMOG communities show a greater degree of Gemeineschaft [18]. Such social environment promotes cohesion among the members and increases social proximity among them [18], which in turn creates a safe space for establishing personal relationships which offer similar support as real-life interaction [21]. Research on social support from MMOG relationships and associated levels of depression in players demonstrated that higher social involvement in MMOG communities resulted in a greater level of perceived social support, which consequentially led to lower levels of depression [21].

On a different note, but still relevant, because studies have shown that emotional and physical pain share a lot of common properties [22], [23], playing video games might also have an analgesic effect. In patients undergoing treatment for severe burns,

\begin{tabular}{llllll}
\hline 62 & Journal of Intelligent Computing Volume & 10 & Number 2 & June & 2019 \\
\hline
\end{tabular}


playing video games proved successful in their pain management [24]. When conducting a study in treatment of combat-related burns where pharmacological therapy was complemented with VR gaming, the perceived pain intensity score fell from 6.25 to 4.50 out of 10 , unpleasant feelings related to pain dropped from 6.25 to 2.83 out of 10 , and the time spent thinking about the pain dropped from $76 \%$ during no VR to $22 \%$ during VR-coupled treatment [25]. It is suggested that inputs from intense, fast-paced immersive virtual environment distract the brain from processing the pain by disturbing the descending pain-control system, which results in painattenuating effects [26].

\subsection{Collaboration and Problem Solving}

In addition, in the last decade a subset of these games has tried to tackle some of the many problems which trouble our society and attempted to gamify real life problems. One of the first games which was successful in harnessing the gamers' superior spatial and problem-solving skills was Foldit in 2008 [27]. The objective of the game was to predict the native structure of various proteins to help the scientists to better understand the molecules. Over 50,000 players collaboratively interacted with protein models using user-friendly manipulation tools, and at the end of 2010 their results matched or outperformed algorithmically computed solutions. Foldit players achieved 'an epic win' in 2011, when they successfully deciphered the structure of an enzyme which is critical for reproduction of the HIV/AIDS virus - a problem which had been previously unsolved for 15 years [28]. Following in Foldit's steps is Eterna, a similar online gaming tool, which asks players to solve puzzles in order to design molecular medicines in collaboration with Stanford's School of Medicine [29]. The mechanisms which are responsible for the success of gamification in solving difficult tasks are probably the same learning-promoting mechanisms described in 3.1.

\section{Conclusion}

I summarized important benefits of playing video games, which can be mainly characterized as improved motor, cognitive, social, emotional and problem solving skills. Is there something as a benevolent brain manipulation? I dare say there is, and as studies suggest, playing games moderately and in a responsible way can serve as a therapeutic and cognitive enhancement tool despite the dangers inherent to gaming technologies.

\section{References}

[1] Anderson, C. A., Shibuya, A., Ihori, N., Swing, E. L., Bushman, B. J., Sakamoto, A., Rothstein, H.R., Saleem, M. (2010). Violent video game effects on aggression, empathy, and prosocial behavior in Eastern and Western countries: A meta-analytic review. Psychological Bulletin, 136 (2), 151-173. DOI: http://doi.org/10.1037/a0018251

[2] Gentile, D. A., Lynch, P. J., Linder, J. R., Walsh, D. A. (2004). The effects of violent video game habits on adolescent hostility, aggressive behaviors, and school performance. Journal of Adolescence, 27(1), 5-22. DOI: http://doi.org/https://doi.org/10.1016/ j.adolescence.2003.10.002

[3] Stockdale, L., Coyne, S. M. (2018). Video game addiction in emerging adulthood: Cross-sectional evidence of pathology in video game addicts as compared to matched healthy controls. Journal of Affective Disorders, 225, 265-272. DOI: http://doi.org/ 10.1016/j.jad.2017.08.045

[4] Turel, O., Romashkin, A., Morrison, K. M. (2016). Health Outcomes of Information System Use Lifestyles among Adolescents: Videogame Addiction, Sleep Curtailment and Cardio-Metabolic Deficiencies. PLOS ONE, 11 (5), e0154764. Retrieved from https://doi.org/10.1371/journal.pone.0154764

[5] Palaus, M., Marron, E. M., Viejo-Sobera, R., Redolar- Ripoll, D. (2017). Neural Basis of Video Gaming: A Systematic Review. Frontiers in Human Neuroscience, 11, 248. DOI: http://doi.org/10.3389/fnhum.2017.00248

[6] Safire, W. (2002). Our New Prometean Gift. In S. J. Marcus (ed.), Neuroethics: Mapping the Field. San Francisco: Dana Press. Retrieved September 1, 2018, from http://dana.org/Cerebrum/2002/Neuroethics__Mapping_the_Field/.

[7] Frank, A. (2013). The Future Of Gaming - It May Be All In Your Head. Forbes. Retrieved September 7, 2018, from https:// www.forbes.com/sites/singularity/2013/06/03/thefuture-of-gaming-it-may-be-all-in-yourhead/\#7839776b7790

[8] Granic, I., Lobel, A., Engels, R. C. M. E. (2014). The benefits of playing video games. The American Psychologist, 69 (1) 6678. DOI: http://doi.org/10.1037/a0034857

[9] Green, C. S. (2013, December 16). Neurogaming: What's Neuroscience and Ethics Got To Do With It? - Exploring Ethics. 
[video file] Retrieved September 7, 2018, from https://www.youtube.com/watch?v=apFE6AR9214

[10] Bao, S., Chan, V. T., Merzenich, M. M. (2001). Cortical remodelling induced by activity of ventral tegmental dopamine neurons. Nature, 412 (6842), 79-83. DOI: http://doi.org/10.1038/35083586

[11] DeYoung, C. (2013). The neuromodulator of exploration: A unifying theory of the role of dopamine in personality. Frontiers in Human Neuroscience, 7, 762. DOI: http://doi.org/10.3389/fnhum.2013.00762

[12] Davies, D., Jindal-Snape, D., Collier, C., Digby, R., Hay, P., Howe, A. (2013). Creative learning environments in educationA systematic literature review. Thinking Skills and Creativity, 8, 80-91. DOI: http://doi.org/https://doi.org/10.1016/ j.tsc.2012.07.004

[13] Green, C. S., Bavelier, D. (2003). Action video game modifies visual selective attention. Nature, 423(6939), 534-537. DOI: http://doi.org/10.1038/nature01647

[14] Li, L., Chen, R., Chen, J. (2016). Playing Action Video Games Improves Visuomotor Control. Psychological Science, 27 (8) ,1092-1108. DOI: http://doi.org/10.1177/0956797616650300

[15] Li, R. W., Ngo, C., Nguyen, J., Levi, D. M. (2011). Video-game play induces plasticity in the visual system of adults with amblyopia. PLoS Biology, 9 (8), e1001135. DOI: http://doi.org/10.1371/journal.pbio.1001135

[16] Franceschini, S., Gori, S., Ruffino, M., Viola, S., Molteni, M., \& Facoetti, A. (2013). Action video games make dyslexic children read better. Current Biology: CB, 23 (6), 462-466. DOI: http://doi.org/10.1016/j.cub.2013.01.044

[17] Schlickum, M. K., Hedman, L., Enochsson, L., Kjellin, A., \& Fellander-Tsai, L. (2009). Systematic video game training in surgical novices improves performance in virtual reality endoscopic surgical simulators: a prospective randomized study. World Journal of Surgery, 33 (11), 2360-2367. DOI: http://doi.org/10.1007/s00268- 009-0151-y

[18] Simpson, J. M., Knottnerus, J. D., Stern, M. J. (2018). Virtual Rituals: Community, Emotion, and Ritual in Massive Multiplayer Online Role-playing Games-A Quantitative Test and Extension of Structural Ritualization Theory. Socius, 4, 2378023118779839. DOI: http://doi.org/10.1177/2378023118779839

[19] Szell, M., \& Thurner, S. (2010). Measuring social dynamics in a massive multiplayer online game. Social Networks, 32(4), 313329. DOI: http://doi.org/https://doi.org/10.1016/j.socnet.2010.06.001

[20] Tönnies, F., Hollis, M. (2001). Community and Civil Society. (J. Harris, ed.) (1 $1^{\text {st }}$ ed.). Cambridge: Cambridge University Press. DOI: http://doi.org/10.1017/CBO9780511816260.006

[21] Dupuis, E. C., Ramsey, M. A. (2011). The relation of social support to depression in massively multiplayer online role-playing games. Journal of Applied Social Psychology, 41(10), 2479-2491. DOI: http://doi.org/10.1111/j.1559-1816.2011.00821.x

[22] Eisenberger, N. I., Lieberman, M. D., Williams, K. D. (2003). Does rejection hurt? An fMRI study of social exclusion. Science, 302(5643), 290-292. DOI: http://doi.org/10.1126/science.1089134

[23] Kross, E., Berman, M. G., Mischel, W., Smith, E. E., Wager, T. D. (2011). Social rejection shares somatosensory representations with physical pain. Proceedings of the National Academy of Sciences, 108 (15), 6270-6275. DOI: http://doi.org/10.1073/ pnas. 1102693108

[24] Hoffman, H. G., Doctor, J. N., Patterson, D. R., Carrougher, G. J., Furness, T. A. $3^{\text {rd }}$. (2000). Virtual reality as an adjunctive pain control during burn wound care in adolescent patients. Pain, 85(1-2), 305-309.

[25] Maani, C. V, Hoffman, H. G., Morrow, M., Maiers, A., Gaylord, K., McGhee, L. L., DeSocio, P. A. (2011). Virtual reality pain control during burn wound debridement of combat-related burn injuries using robotlike arm mounted VR goggles. The Journal of Trauma, 71 (1 Suppl), S125-30. http://doi.org/10.1097/TA.0b013e31822192e2

[26] Gold, J. I., Belmont, K. A., Thomas, D. A. (2007). The Neurobiology of Virtual Reality Pain Attenuation. Psychology \& Behavior, 10 (4), 536-544. http://doi.org/10.1089/cpb.2007.9993

[27] Cooper, S., Khatib, F., Treuille, A., Barbero, J., Lee, J., Beenen, M., Leaver-Fay, A., Baker, D., Popovi, Z. and Foldit players (2010). Predicting protein structures with a multiplayer online game. Nature, 466(7307), 756-760. DOI: http://doi.org/10.1038/ nature09304

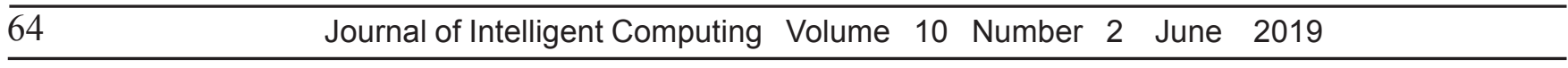


[28] Foldit. In: Wikipedia. Retrieved September 7, 2018, from https://en.wikipedia.org/wiki/Foldit

[29] Eterna Game. [Web page] Retrieved September 9, 2018, from https://eternagame.org/ 